\title{
Oxidative Stress and Inflammation
}

\author{
Samreen Soomro \\ Department of Basic Health Science, Faculty of Pharmacy Northern Border University, Rafha, Saudi Arabia \\ Email: soomro.samreen@gmail.com
}

How to cite this paper: Soomro, S. (2019) Oxidative Stress and Inflammation. Open Journal of Immunology, 9, 1-20. https://doi.org/10.4236/oji.2019.91001

Received: February 6, 2019

Accepted: March 28, 2019

Published: March 31, 2019

Copyright (c) 2019 by author(s) and Scientific Research Publishing Inc. This work is licensed under the Creative Commons Attribution International License (CC BY 4.0).

http://creativecommons.org/licenses/by/4.0/

\begin{abstract}
Inflammation is a part of the complex biological response of vascular tissues to harmful stimuli. Debilitating diseases such as atherosclerosis, rheumatoid arthritis, and even cancer are the biggest pharmacological hurdles of today. Targeting inflammation is a broad task, since many mediators are involved in onset of particular disease. Among these many mediators, the reactive oxygen and nitrogen species generated by macrophages and neutrophils are of great interest because of their major contribution in establishment of chronic inflammation and cancer. This review elaborates the pathogenesis of inflammation based on involvement of reactive oxygen and nitrogen species and the activation of signalling cascades in response to oxidative stress. Understanding this would eventually give a clue for target based therapeutic approach in search of new effective anti-inflammatory drugs.
\end{abstract}

\section{Keywords}

Oxidative Stress, Nitric Oxide, ROS, NFKB, Inflammation

\section{Introduction}

Patients with chronic inflammatory diseases are increasing, particularly those associated with hyper responsive immune system, including asthma, inflammatory bowel disease (IBD), chronic fatigue syndrome, atherosclerosis and rheumatoid arthritis. The biggest pharmacological hurdles of today are to treat such chronic inflammatory disorders. Furthermore, diseases like multiple sclerosis, chronic asthma, rheumatoid arthritis, psoriasis, and inflammatory bowel disease, are strongly debilitating and are becoming progressively more common among aged people in our society. People affected worldwide with bones diseases like rheumatoid arthritis and osteoarthritis are the major victims of these inflammatory disorders. In this regard, the fourth leading cause of disability by the year 2020 would be osteoarthritis, in aging populations. Moreover, several epidemio- 
logical studies have shown inflammation as one of the major risk factors in emerging various kinds of neoplastic transformation [1].

Inflammation is s part of the complex biological response of vascular tissues to harmful stimuli [2]. It is a protective reaction of body's cells to injury or infections and allergic or chemical irritation. This is a reaction that is characterized by certain inflammatory features which are redness, pain, swelling, heat, and loss of function because of the blood vessels dilation that leads to the increase of blood flow in that area, thus resulting in the migration of immune cells like neutrophils and macrophages, along with the fluids causing edema toward the inflamed regions. The process of inflammation is quite complex, initiated by several factors which include molecules that ranges from bacteria to chemical and therefore results in cellular trauma or death. Tissue injury induced by this trauma results in the inflammatory mediators release including reactive oxygen species (ROS) like superoxide anion $\left(\mathrm{O}^{2-}\right)$, hydrogen peroxide $\left(\mathrm{H}_{2} \mathrm{O}_{2}\right)$, nitric oxide and cytokines [3]-[8]. Immune system disorders have been linked to increased expression of pro-inflammatory mediators, including cytokines, NADPH oxidase, NF kappa B, myeloperoxidase, and Inos [9].

Pharmacological and physiological constituents of the herbal medicines are known to regulate and modulate various functions of inflammatory response in the body either directly or indirectly [10]. The highly complex immune system is however containing well organized set of cells and each cell in this group has a defined function which is particularly essential to protect the body from diseases. Immune cells may interact in a cell to cell manner and also act in response to intercellular messages during the transfer of hormones, and cytokines [11]. Peripheral immune system comprises of, lymphocytes leukocytes, mast cells, and platelets, whereas in central nervous system, the cells that amend inflammatory reactions are, microglial cells, endothelial cells and astrocytes [12] [13] [14] [15].

Major incidents of inflammatory reaction that trigger robust hyperactive immune response could be summarizing in following five categories. First: Nitric Oxide (NO) and prostaglandin synthesis [16], second: NF kappa B expression, third: reactive oxygen species (ROS) [17], fourth: migration of leukocytes [18], and finally the fifth: is increased production of pro-inflammatory cytokines i.e. TNF, IL6 and IL1 [19].

\section{Role of the Free Radicals in Pathology of Inflammation}

Reactive oxygen and nitrogen species generated by macrophages and neutrophils Figure 1 upon encounter of an antigen or allergen have been shown its implication in immune system disorders. This phenomenon of generation of free radicals is known as oxidative burst which is accomplished by involvement of $\mathrm{NADPH}$ oxidase, present on the surface of neutrophils membrane. The NADPH oxidase which is reactive oxidant producing enzyme or by inducible nitric oxide synthase (iNOS) expressed in activated phagocytic cells both reactive nitrogen and reactive oxygen species are discussed in detail below [20]-[25]. 


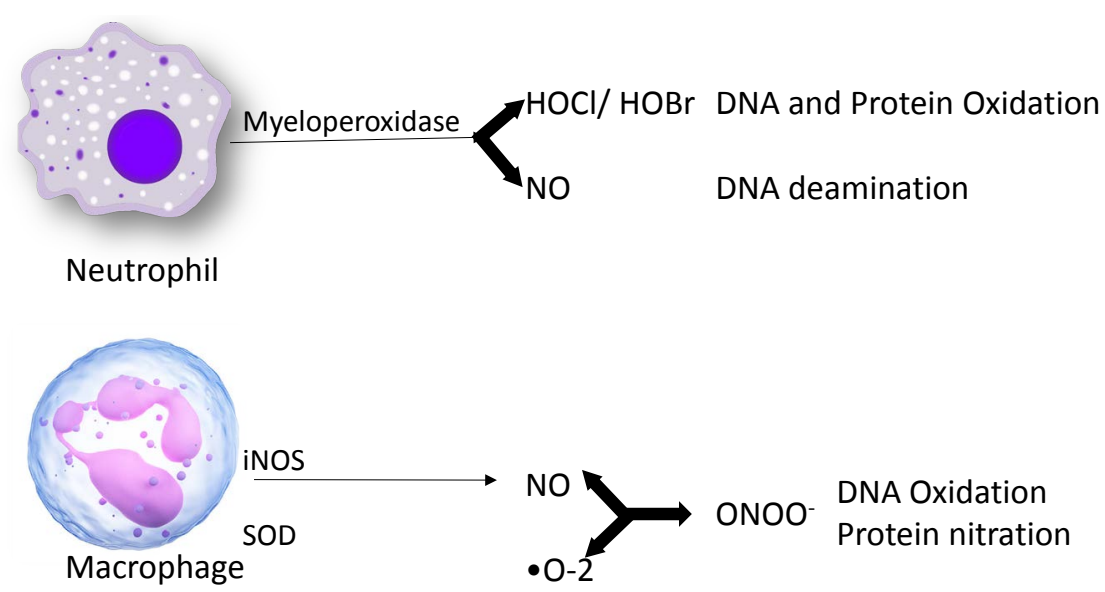

Figure 1. Free radical species generated during inflammation.

\section{Nitric Oxide}

Under normal conditions, Nitric oxide (NO) is known to participate in physiological processes, such as vasodilatation and neurotransmission, however, over expression of this molecule have been documented to lead to diseases like asthma, inflammation, atherosclerosis and organ transplant rejection. Many other factors such as the persistent inflammation of the stomach commonly caused by the pathogenic bacterium, Helicobacter pylori, chronic obstructive pulmonary disease and liver inflammation caused by smoking and alcohol consumption that leads to lung cancer and liver cirrhosis respectively. Therefore, tissue inflammation from gastritis, hepatitis, and colitis are all correlated with enhanced NO production. For instance, in inflammatory cells, the inducible nitric oxide synthase when activated, it induces iNOS activation in macrophages, hence cause persistence NO production. NO produced in this way shows toxicity to cells and damage to the surrounding tissue. Nevertheless, when NO produced by constitutive forms of NOS, proven essential to sustain the normal function of cells [26]-[32].

During the inflammatory conditions, cell expresses iNOS, which is considered to be regulated primarily at the level of gene expression. Once expressed, iNOS is thought to constantly produce NO in presence of an adequate substrate as well as cofactors needed, until degradation of iNOS protein [33].

These properties have led to the conclusion that iNOS generates NO in an unregulated fashion with mainly cytotoxic properties. Hence scientists start believing that nitric oxide (NO) is one of the major mediators which cause inflammation and cancers in several organs. For instance, the excessive production of this free radical become more toxic to the host tissue, when react with superoxide radicals which is directly damaging specie for the normal functions of cells. There are two other major forms of nitric oxide synthase NOs, the endothelial (eNOS) and the neuronal nitric oxide synthase (nNOS) which already known now beside the inflammatory iNOS. The iNOS $(130 \mathrm{kDa})$ is the inducible form of enzyme, primarily found in macrophages as a homodimer under native 
conditions, However, for fully functional enzymatic activity depends upon tetrahydrobiopterin-dependent dimerization. In cases where inflammation continues over months or even years, the nearby cells may be exposed to considerable quantities of highly reactive chemical species eventually, leading to debilitating diseases [26] [34] [35] [36] [37].

\subsection{Cellular Activation}

Toll Like Receptors are type I transmembrane receptors with a single membrane-spanning domain, and a leucine-rich extracellular ligand-binding domain that contains repeats of a non-polar amino acid leucine, and an intracellular Toll like receptor domain. There are number of human TLRs functioning either as homodimer or heterodimers, these receptors are known to be involved in recognition of particular set of pathogen-associated molecular patterns (PAMPs). For examples the LPS activate the TLR4. An array of an external stimulus has been recognized to activate distinctive signaling pathways that initiate expression of the proinflammatory iNOS [38] [39].

\subsection{Signaling that Trigger the NO Release by Macrophages}

Cell wall of Gram-negative bacteria comprise of good amount of LPS (Lipopolysaccharide), Figure 2 this LPS could serve as an initiator for inflammatory cascades. The LPS upon encounter to a cell, it interacts with LPS Binding Protein LBP, which in turn delivers LPS to CD14, the CD14-LPS complex with the help of MD2 (Lymphocyte antigen 96) interacts with TLR4, leading to initiation of signaling pathway via adaptors molecules that are MyD88 and IRAK p38, TRAF6, and TAB1 by these adaptors is done. Eventually TLR4 activation by LPS leads to NF- $\mathrm{KB}$ activation. NF- $\mathrm{KB}$ is pleotropic transcription factor which is

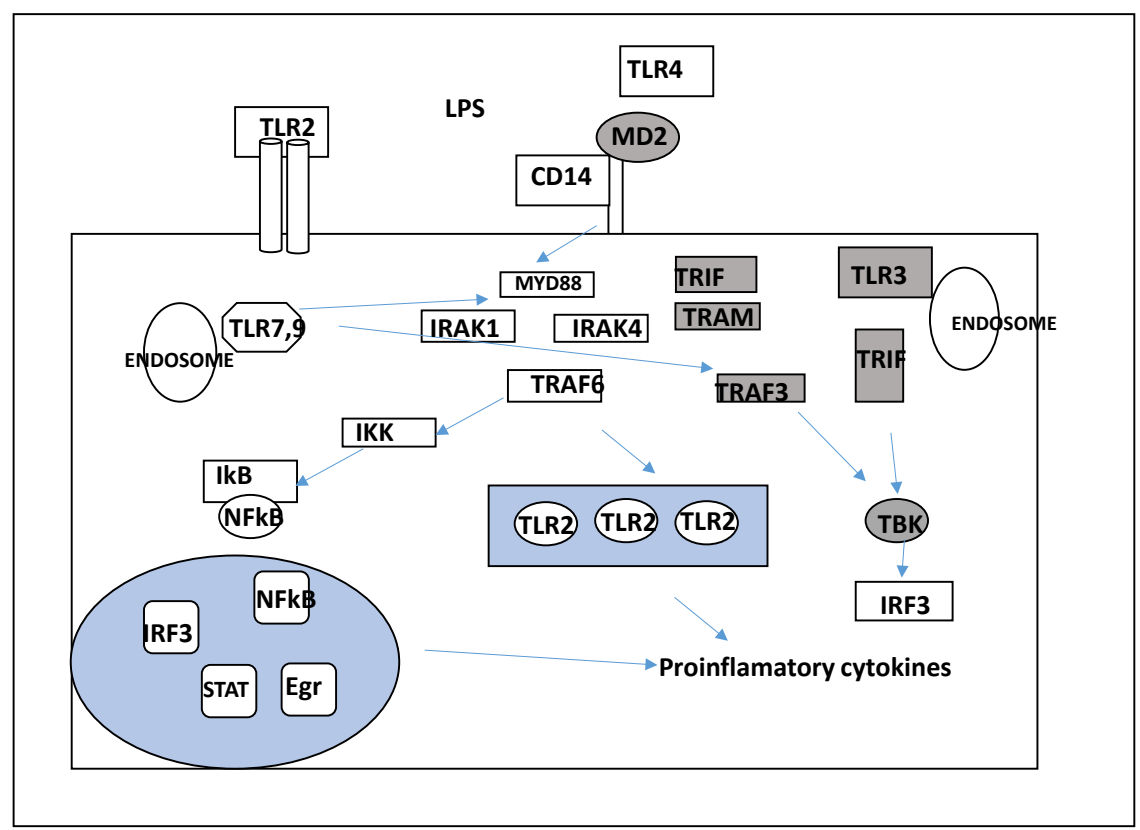

Figure 2. LPS induced signaling pathway. 
present in almost all cell types and is involved in many biological processes such as inflammation, immunity cell growth differentiation, and tumorigenesis. The $\mathrm{NF}-\mathrm{\kappa B}$ is a homo or hetero dimer, compose of Rel like domain containing pro-

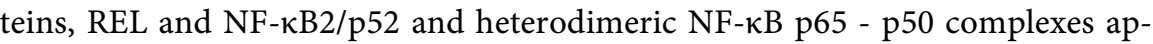
pear to be one of the most abundant protein in the cell, the dimer binds at kappa $\mathrm{B}$ site in the DNA and act as transcriptional activator or repressor respectively. NF- $\kappa B$ complex is held in cytoplasm by in an inactive state complexed with member of NF- $\kappa B$ inhibitor I- $\kappa B$ family [40] [41] [42] [43] [44].

In a conventional activation pathway, $\mathrm{I}-\kappa \mathrm{B}$ is phosphorylated by $\mathrm{I}-\kappa \mathrm{B}$ kinase (IKK) in response to different activator subsequently degraded thus liberating the active NF- $\mathrm{BB}$ complex which translocate to the nucleus, NF- $\mathrm{kB}-\mathrm{p} 65-\mathrm{p} 50$ complex is a transcriptional activator it sits on $\mathrm{kB}$ elements in the iNOS 5 site, triggering iNOS transcription. Additionally, cytokines released from infected host cells, TNF- $\alpha$ and IL- $1 \beta$ also known to activate NO production The IFN- $\gamma$ cytokine interacts with the IFNR1 and IFNR2 complex, and causes the activation of JAK/STAT pathways, leading to the synthesis of IRF1transcription factor and stimulation of iNOS mRNA transcription [45] [46] [47].

The IFN- $\gamma$ also found to provides a synergistic effect to the LPS induction of iNOS transcription because IRF1 interacts with NF- $\mathrm{kB}$, altering the conformation of the NOS2 promoter. They enhances the binding of transcription factors, such as NF- $\kappa$ B and AP-1, by DNA-protein and protein-protein interactions [48].

\section{Reactive 0xygen Species (ROS)}

NADPH oxidase is activated during inflammation, resulting in generation of superoxide $\left(\cdot \mathrm{O}^{-2}\right)$ and by action of superoxide dismutase (SOD), it gets connected to $\mathrm{H}_{2} \mathrm{O}_{2}$. Further chloride gets involve and makes $\mathrm{H}_{2} \mathrm{O}_{2}$ more toxic, in presence of myeloperoxidase, which usually activated by neutrophils and results in formation of very toxic $\mathrm{HOCl}$, Figure 3. Therefore, the enzymes NADPH Oxidase is normally found in a resting state and function in redox signaling as second messenger. However, under abnormal conditions stimulated phagocytes involved in oxidative stress.

The NADPH oxidase complex is a cluster of proteins that donate an electron from NADPH to molecular oxygen $\left(\mathrm{O}_{2}\right)$ to produce superoxide $\left(\mathrm{O}_{2}^{-}\right)$. This initiates the respiratory burst, a key step in immune defense against bacterial and fungal pathogens. The importance of this process to human health is manifested in chronic granulomatous disease (CGD), which refers to any of several hereditary diseases in which certain oxidase proteins are defective. The result is a reduce superoxide production and impaired clearance of bacterial pathogens, leading to the formation of a granuloma, or fibrotic nodule, around the persistent bacterial infection. While CGD underscores the significance of NADPH oxidase in professional phagocytes, like neutrophils, monocytes, and macrophages, NADPH oxidase has additional roles in other cell types. These non-phagocytic versions of the NADPH oxidase produce less superoxide, which is involved predominantly in the inter- and intra-cellular signaling [49] [50] [51] [52] [53]. 


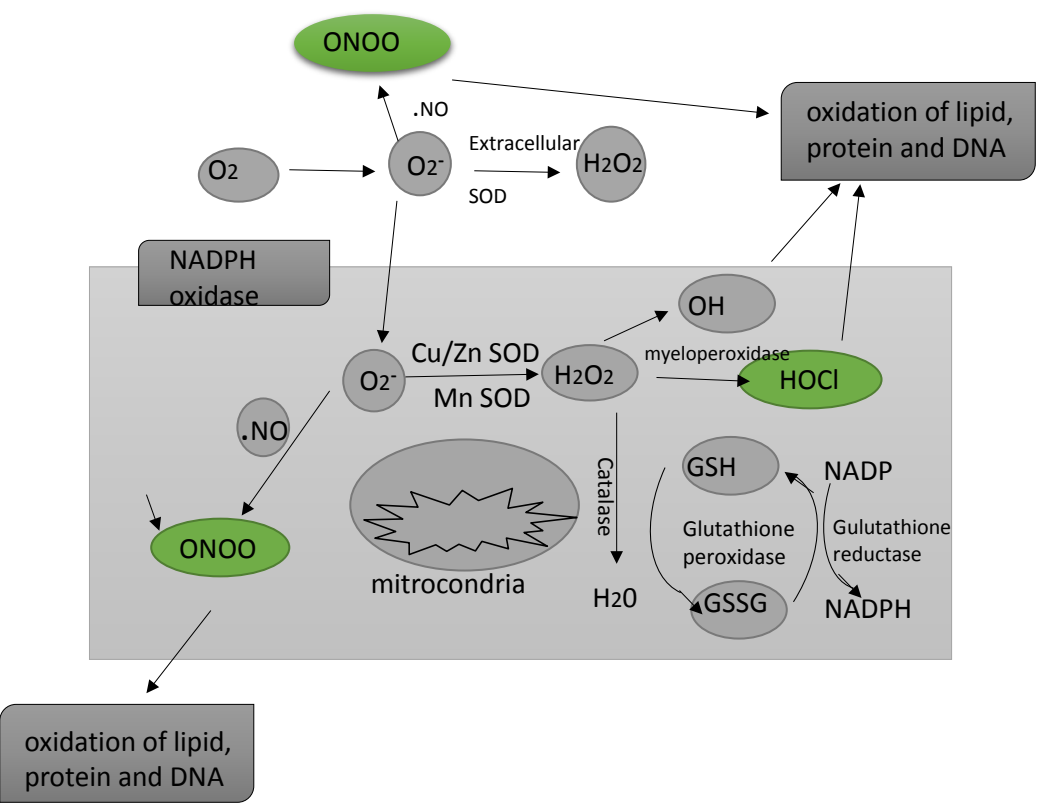

Figure 3. Major pathways involved in the intracellular production of reactive oxygen/nitrogen species.

\subsection{Cellular Activation}

A variety of stimuli can lead to superoxide production through NADPH oxidase, but in the phagocytes, a very strong response is known be achieved through ligand that activates Gq-type GPCRs. Some of the molecules that activates specific Gq-coupled receptors include PAF, IL-8, various proteases, nucleotides like ATP, and N-formylated peptides (fMLP). Receptor activation causes Gq to initiate hydrolysis of membrane-associated phosphatidylinositol bisphosphate $\left(\mathrm{PIP}_{2}\right)$ by phospholipase $\mathrm{C} \beta(\mathrm{PLC} \beta)$, giving rise to inositol trisphosphate $\left(\mathrm{IP}_{3}\right)$ and diacylglycerol (DAG). The $\mathrm{IP}_{3}$ promotes the opening of calcium $\left(\mathrm{Ca}^{2+}\right)$ channels in the endoplasmic reticulum (ER), leading to a transient rise in intracellular $\mathrm{Ca}^{2+}$ levels. It is an established fact that both $\mathrm{Ca}^{2+}$ and DAG activate PKC, which results in its movement from the cytoplasm to a membrane. $\mathrm{Ca}^{2+}$ also activates cytosolic $\mathrm{PLA}_{2}\left(\mathrm{CPLA}_{2}\right)$, which moves to the ER and perinuclear membranes to selectively liberate arachidonic acid (AA) stored in membrane phospholipids. The AA is known to act as a second messenger and is believed to regulate many neutrophil functions, although the underlying mechanisms and its physiologic role are poorly understood. Stimulation of intact neutrophils with exogenous AA leads to activation of PKCs, phosphatidylinositol 3-kinases (PI-3K), PLC, PLD, and mitogen-activated protein kinases (MAPK). Exogenous AA has long been known to activate neutrophil superoxide [54] [55].

\subsection{Assembly of the NADPH Oxidase Complex}

In the resting phagocytes, a portion of the oxidase is integrated in membranes while other components remain soluble in cytoplasm (Figure 4). The membrane-bound section consists of a large glycosylated protein, gp91 ${ }^{\text {phox }}$, and a smaller 


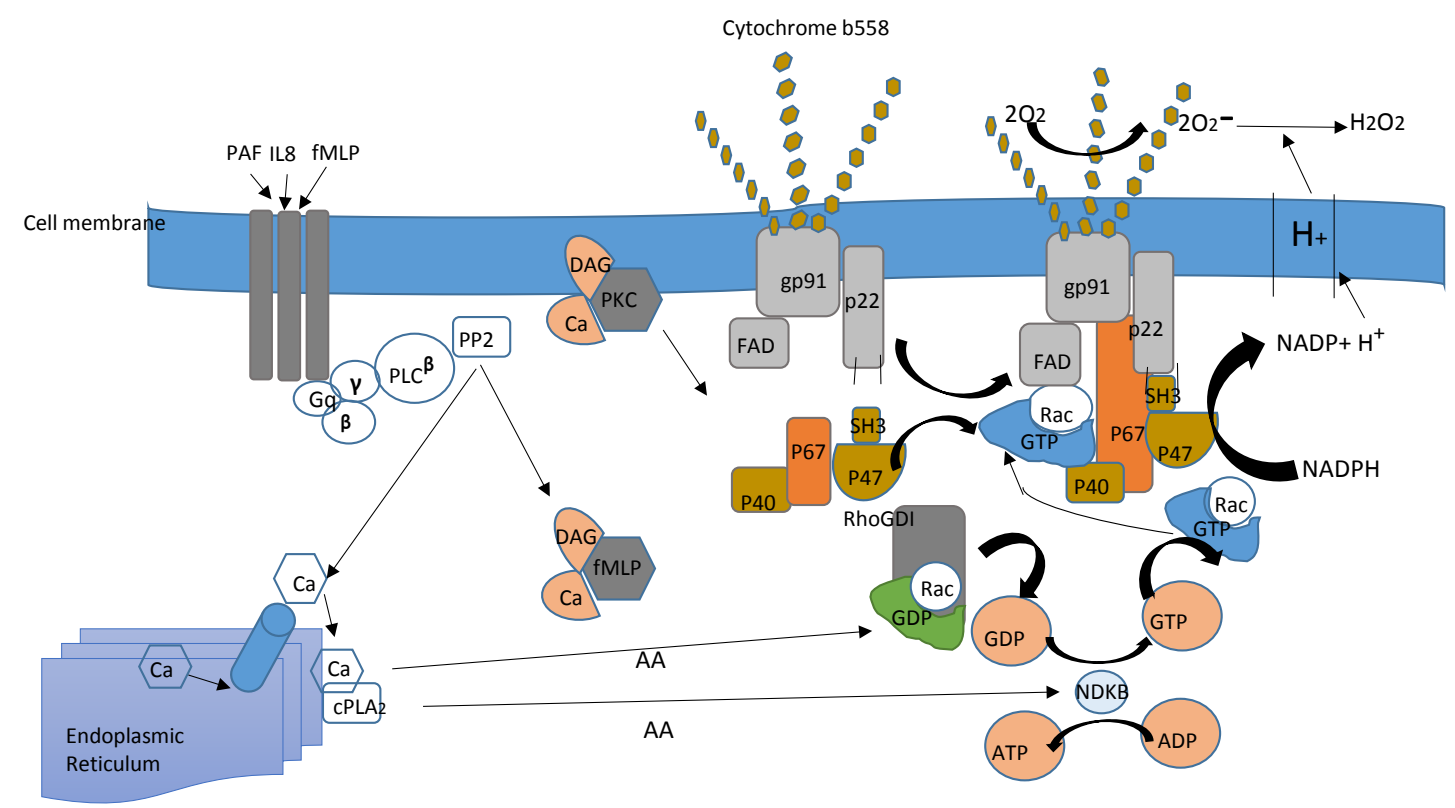

Figure 4. The NADPH oxidase complex.

adapter protein, $\mathrm{p} 22^{\text {phox }}$, collectively referred to as cytochrome b558. The gp91 ${ }^{\text {phox }}$ protein contains two heme groups and binds the redox cofactor flavin adenine dinucleotide (FAD), suggesting that it is the workhorse of the oxidase. The GTPase rap1 is also sometimes described as associated with cytochrome b558, but this association, as well as the function of rap1, remains controversial. The $\mathrm{p} 47^{\text {phox }}, \mathrm{p} 67^{\text {phox }}$, and $\mathrm{p} 40^{\text {phox }}$, proteins are found linked together by $\mathrm{SH} 3$ domains and $\mathrm{SH} 3$ binding sites. Cell stimulation through a Gq-coupled receptor drives PKC-mediated phosphorylation of $4^{\text {phox }}$ on several residues, resulting in the translocation of this soluble complex to the bound complex at the membrane, with $\mathrm{p} 47^{\text {phox }}$ binding to $\mathrm{p} 22^{\text {phox }}$ through an $\mathrm{SH} 3$ domain. It is important to note that $\mathrm{p} 47^{\text {phox }}$ can be phosphorylated by several other kinases (e.g., Akt, MAPK, c-Src), which in turn are activated by distinct stimuli. Over a dozen sites on $\mathrm{p} 47^{\text {phox }}$ have been shown to be phosphorylated; the role(s) of each of these modifications are important areas of current research. However, it is clear that phosphorylation of $\mathrm{p} 47^{\mathrm{phox}}$ alters its shape, enabling translocation and activity. The $p 67^{\text {phox }}$ is absolutely essential for full oxidase activity and in transferring electrons from NADPH to FAD; it is phosphorylated on $\mathrm{Thr}^{233}$ during cell activation. The $\mathrm{p} 40^{\text {phox }}$ appears to serve a negative regulatory role within the NADPH oxidase complex, with phosphorylation on $\mathrm{Thr}^{154}$ affecting this role [56] [57] [58] [59].

\subsection{The Trigger for ROS}

Phorbol esters are among the most potent activators of the neutrophil respiratory burst, acting as analogs of diacylglycerol (DAG) and directly activating many members of the serine-threonine protein kinase C (PKC) family. The downstream effects of PKC include direct phosphorylation of $\mathrm{p} 47^{\text {phox }}$, which further 
leads to membrane translocation of cytosolic components in a cell-free system and intact cells. Other activator like chemoattractant Formyl-Met-Leu-Phe (fMLP), immunoglobulin $\mathrm{G}$ (IgG)-opsonized zymosan or other bacteria processed by engulfing through receptors, coat the surface of professional phagocytes. Similarly, receptor binding initiates a cascade of signals that culminate in the cell membrane engulfing the bacterium in a vesicle, the phagosome. Along with the bacterium the membrane proteins will be internalized which includes cytochrome b558 (gp91/p22) and FAD; these and other membrane-bound proteins will also be delivered to the internalized phagosome as it gets matures. Receptor signaling activates kinases that phosphorylate soluble phox proteins to initiate assembly of the NADPH oxidase complex [58] [60] [61].

\subsection{Phagocytosis}

The phagosome pocket is formed in response to antigen engulfment by phagocytes, where a series of vesicles fuse with the phagosome to aggressively destroy and take part the foreign pathogen. Granules from rapidly deliver pre-formed enzymes, include defensing, myeloperoxidase, gelatinases, and cathepsins, to the maturing phagosome, aiding in killing. During maturation of early to late endosomes soluble and membrane-bound proteins are delivered from the endoplasmic reticulum and Golgi to the phagosome. Finally, lysosomes infuse digestive enzymes that function in the acidic conditions of the mature phagosome, degrading the bacterium. The entire process of bacterial capturing, killing, and degradation can take place in time spam of less than 60 mints. In phagocytes which also act as antigen-presenting cells, portions of digested prey may be recirculated to the cell surface for presentation to lymphocytes to propagate the immune response [62] [63].

\section{Pathogenesis of ROS/NO}

During inflammation the inducible form of nitric oxide synthase becomes activated and causes the robust generation of NO that causes excessive vasodilation resulting in hypotension, and septic shock. This may result in fatal complications in older age, and in young people during bacterial infection leading to sepsis. One of the most toxic radical derived from $\mathrm{NO}$ is peroxynitrite $\left(\mathrm{ONOO}^{-}\right)$ that is generated when NO combines with superoxide (ROS)-released during phagocytosis. The $\mathrm{ONOO}^{-}$generation, eventually reduces the bioavailability of basal NO and, therefore, affect its function on endothelial relaxation causing vasoconstriction, and hypertension, which may lead to atherosclerosis. On the other hand, excess formation of $\mathrm{ONOO}^{-}$causes nitrosylation of proteins, which contributes in cancer development. In addition to this, $\mathrm{NO}$ also plays a role in heart and lung diseases, septic shock, as well as in impotence. This wide role of NO in various pathological conditions prompted scientists to develop potent NO inhibitor [64] [65] [66] [67] [68].

Reactive Nitrogen Species such as NO are involved in inflammation-induced 
carcinogenesis, as it known to induce guanine nitration, producing $\mathrm{G}: \mathrm{C}$ to $\mathrm{T}$ :Atransversion. The products of nitric oxide synthesis induce mutations through $N$-nitrosation of secondary amines and may play a critical role in carcinogenesis induced during chronic inflammation because these $N$-nitrosamines are markedly mutagenic. Additionally, peroxynitrite $\left(\mathrm{ONOO}^{-}\right)$is very toxic and causes mutations through DNA strand break and DNA base modification. Furthermore, ROS/RNS can cause enhanced expression of proto oncogenes by DNA base modification, strand breaks, and tumor-suppressor genes disruption. Overall, oxidative stress has been shown to induce malignant transformation of cells in culture. Nevertheless, the progression of human cancer depends on other factors as well, including the extent of DNA damage, DNA repair systems functioning, and the cytotoxic effects of ROS in large amounts as well as their growth-promoting effects in small amounts. For example, the proliferative responses of Syrian hamster embryo fibroblasts to superoxide, and the low levels of $\mathrm{O}^{-2}$ can enhance cell growth, whereas constant unnecessary oxidative DNA damage may ignite signals (like p53 a tumor suppressor gene) and therefore induce apoptosis. In addition, ROS/RNS induced DNA strand breaks results in accumulation of p53 inside the nucleus, the cell growth at the G/S phase is arrested in order to allow DNA to repair its lesions before going in replication phase [69] [70] [71].

\subsection{Targeting iNOS}

NO serve as neurotransmitter under stress conditions whenever, NO concentration increase causes the unnecessary vasodilation leads to hypotension. Different studies have shown that a series of potent and selective inducible nitric-oxide synthase (iNOS) inhibitors prevent dimerization of enzyme iNOS in cells, and inhibit iNOS in vivo. Then inhibitors could be a better therapeutic approach for the above mentioned diseases. However, it is also evident that most of the compound not directly inhibit enzyme, rather inhibition could be at mRNA level or through inhibition of the transcription factor NF-k B Inhibition of the transcription factor could be of therapeutic potential since its pathway is directly involved in chronic inflammatory diseases. Different target sites have been mention in Figure 5 [72] [73] [74] [75].

\subsection{Targeting NADPH Oxidase}

In some inflammatory diseases scientist aim to target Activation of NADPH oxidases which may result from the stimulation of a number of cell surface receptors, such as the angiotensin II receptor, which is particularly important in hypertension and heart failure due to the complex mechanisms involved in the activation of NADPH oxidases, these enzymes can be targeted at several different levels of their activity. Firstly, decreasing NADPH oxidase expression can lead to inhibition. Also, the activation of NADPH oxidase can be decreased by blocking the translocation of its cytosolic subunits to the membrane. Another 


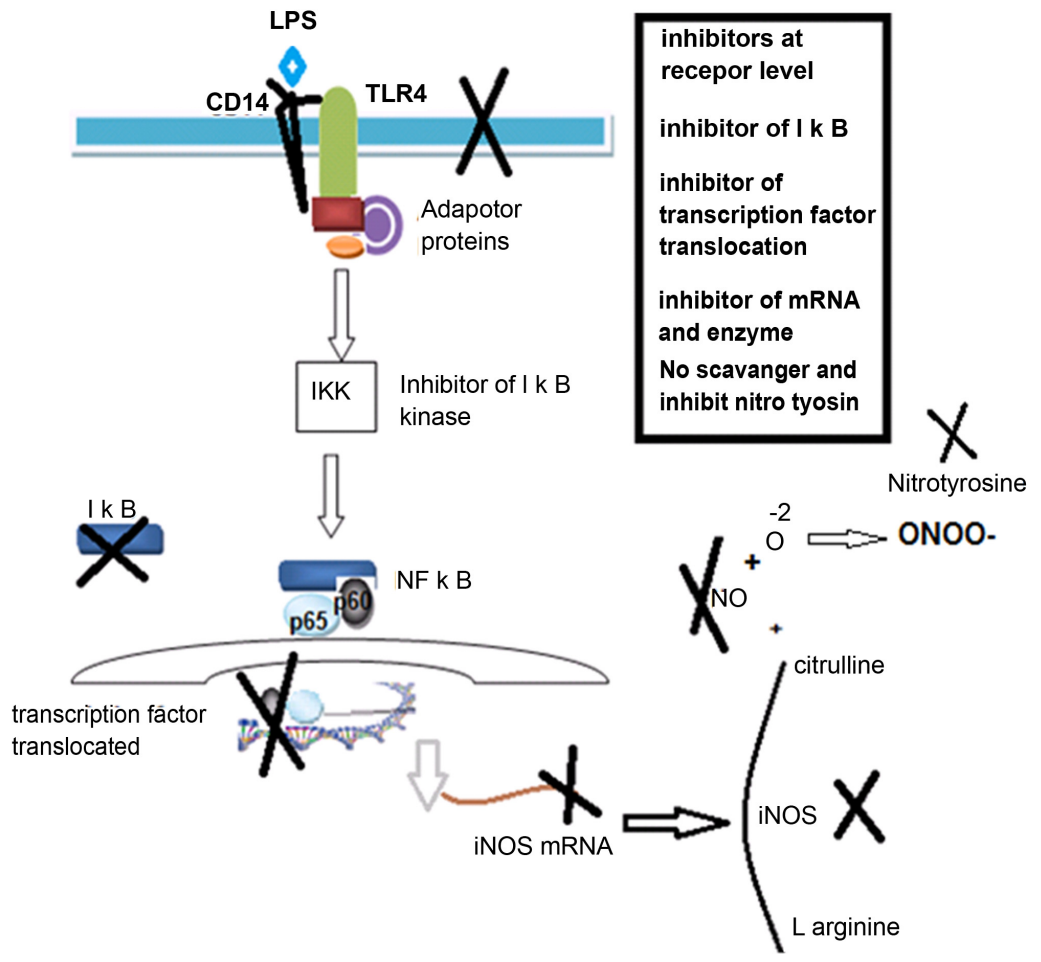

Figure 5. Mechanism of nitric oxide inhibition. Shows the possible target sites in activated macrophages.

possibility is inhibition of the $47^{\text {phox }}$ subunit, either by preventing its phosphorylation using PKC inhibitors, or by blocking its binding to other subunits. A decrease of signal transduction and inhibition of Rac 1 translocation have also been demonstrated to decrease ROS generation [76] [77].

NADPH oxidase is multisubunit membrane protein that is activated by translocation of the cytosolic subunits $\mathrm{p} 47^{\text {phox }}, \mathrm{p} 67^{\text {phox }}$, and Rac to the Nox $/ \mathrm{p} 22^{\text {phox }}$ complex. Some of the inhibitors act by interfering with this translocation. Nonspecific inhibitors target the flavin-containing subunit (DPI), the major activators of the oxidase are the ACE inhibitors and angiotensin receptor blockers, whereas upstream kinases, the PKC inhibitors inhibit translocation of p47 subunit. Some inhibitors act as scavenger of the reactive oxygen species known as antioxidants [78] [79].

\section{Anti Inflammatory Drugs in the Molecular Biology Era}

Based on the cellular and molecular pathways involved in progression of inflammation, can be ameliorated and eventually treated with pure compounds pos. It is well known that anti-inflammatory properties of several natural compounds isolated from a verity of plants, e.g, flavonoids and its derivatives, phytosterol, genistein, tocopherol, curcumin ascorbic acid, and others are the widely used inhibitors of the molecular targets of pro-inflammatory mediators in inflammatory drug design research [80] [81].

Other plants that contain triterpenoids, alkaloids, saponins, tannin, and anth- 
raquinones, have been reported to possess a diverse range of bioactivities which includes anticancer, antibacterial, immunomodulating, antimalarial, and anti-tuberculosis activities. Other studies with synthetic derivatives suggested that most of those derivative exhibit potential of anti-inflammatory property by blocking pro inflammatory mediators such as derivatives of thiazole, alkyl derivatives and Bergenin [82] [83].

Currently, a number of drugs in clinical uses possess antioxidant property as an example the Tamoxifen, is a drug of choice and is widely used for the cure of breast cancer it is found to exert antioxidant its effects in addition to the anti oestrogenic properties. It has been reported that it suppresses $\mathrm{H}_{2} \mathrm{O}_{2}$ production in human neutrophils. This drug is given as a prophylactic drug for breast cancer. Another example is the most commonly used drug sulphasalazine which is also found to act as a free-radical scavenger. Sulphasalazine and its metabolites are now used in treatment of IBD. When Sulphasalazine is administered, it gets converted by the colonic bacteria into 5 -aminosalicylic acid (5-ASA), which is powerful antioxidant. It can efficiently scavenge free oxygen redials serving as excellent scavenger of $\mathrm{HOCl}$. The tamoxifen metabolite 4-hydroxytamoxifen inhibitor of lipid peroxidation [84].

\section{Prevention from Oxidative Stress and Need Based Research}

Overall, imbalance between antioxidant defense mechanism and oxygen-derived species generation in vivo leads to state of oxidative stress. There is evidently no great reserve of antioxidant defenses in mammals, perhaps because some oxygen-derived species may involve in metabolism. Certain compounds or strategies cause an activation of mitochondrial oxygen consumption and promote increased formation of ROS formation. These molecules culminating in increased stress resistance and longevity. During aging the oxidative stress of the organism is increasing and approaches to lower the increased ROS formation in our cells should be implemented. The most efficient preventive step to avoid exogenous free-radical exposure would be to avoid, exogenous toxic molecules cigarette smoke, pollutants and UVR, since it's not always possible, protection could be obtained by adequate antioxidant protection, decreasing the formation of free radicals, or increasing damage-repair systems of the cells [85].

Paradoxically, the efficiency of defense and repair may be enhanced by different measures caloric restriction (with adequate vitamin and mineral intake) for the prolonging of life. On the other hand, the reduction of energy metabolism may actually reduce ROS generation from mitochondria and consequently extend lifespan. In either case, avoiding electron leakage from electron transport and the resultant ROS production seem to be essential for a normal life. In order to reduce endogenous oxidative stress lifestyle approach to be followed. Consumption of vegetables and plant-derived foods and beverages has positive effect on the prevention of age associated diseases like coronary heart disease and atherosclerosis as well as for longevity. Avoiding mental stress, meditation and 
limit intake of fats and sugar is another way of preventing from oxidative stress. Besides that, after consuming a meal, perform work instead of resting should in order to maintain an appropriate electron flow. The regulation of energy by the body's circadian rhythms also plays a significant role in controlling oxidative stress [86] [87] [88].

In addition to this if person suffering from inflammation must to cure using the medication however the medications may limit the symptoms but could not provide a complete healing. With advent of NSAIDs physicians treated successfully Rheumatoid Arthritis patients, unfortunately later developed gastrointestinal bleeding, because of long term administration of aspirin along with cortisone. Since that time, the pharmaceutical industry and researchers are trying to find solution and new ways to overcome the gastrointestinal toxicity caused by this effective drug of choice which is combination of steroids plus NSAIDs. Recently researcher is investigating anti-inflammatory entities that are immunomodulating which possess inhibitory activity against oxidative stress particularly with specific targeted molecule. Eventually, this information can be useful in the theoretical design of drugs with favorable, improved specificity and activity [89] [90] [91].

\section{Conclusion}

Targeting inflammation is a broad task, since many mediators are involved in onset of particular disease. Among these many mediators, free radicals are of great interest because of their major contribution in establishment of chronic inflammation and cancer. The well known immunosuppressive and anti-inflammatory drugs that are commercially available are mainly non-selective in their mechanism of action and also exhibit numerous side effects. The purpose of current review is to understand the new target site via targeting oxidative stress in terms of nitric oxide and reactive oxygen species at cellular level. This might work to develop new anti-inflammatory molecules with specific target. As mentioned above, inducible nitric oxide synthase and phagocytic NADPH oxidase can be focused so that specific pathologies can be targeted. Keeping this in mind, the potential of anti-NADPH oxidase and iNOS inhibitors, could serve as promising therapeutic intervention for chronic inflammatory disorders.

\section{Conflicts of Interest}

The author declares no conflicts of interest regarding the publication of this paper.

\section{References}

[1] Kanwar, J.R., Kanwar, R.K., Burrow, H. and Baratchi, S. (2009) Recent Advances on the Roles of NO in Cancer and Chronic Inflammatory Disorders. Current Medicinal Chemistry, 16, 2373-2394. https://doi.org/10.2174/092986709788682155

[2] Kumar, S., Bajwa, B.S., Kuldeep, S. and Kalia, A.N. (2013) Anti-Inflammatory Activity of Herbal Plants: A Review. International Journal of Advances in Pharmacy, 
Biology and Chemistry, 2, 272-281.

[3] Kumar, V., Abbas, A.K. and Aster, J.C. (2017) Robbins Basic Pathology. E-Book, Elsevier Health Sciences, Amsterdam, 57-97.

[4] Fujiwara, N. and Kobayashi, K. (2005) Macrophages in Inflammation. Current Drug Targets-Inflammation and Allergy, 4, 281-286. https://doi.org/10.2174/1568010054022024

[5] Winrow, V.R., Winyard, P.G., Morris, C.J. and Blake, D.R. (1993) Free Radicals in Inflammation: Second Messengers and Mediators of Tissue Destruction. British Medical Bulletin, 49, 506-522. https://doi.org/10.1093/oxfordjournals.bmb.a072627

[6] Matés, J.M. and Sánchez-Jiménez, F. (1999) Antioxidant Enzymes and Their Implications in Pathophysiologic Processes. Frontiers in Bioscience, 4, 339-345. https://doi.org/10.2741/A432

[7] Chapple, I.L.C. (1997) Reactive Oxygen Species and Antioxidants in Inflammatory Diseases. Journal of Clinical Periodontology, 24, 287-296. https://doi.org/10.1111/j.1600-051X.1997.tb00760.x

[8] Maier, C.M. and Chan, P.H. (2002) Book Review: Role of Superoxide Dismutases in Oxidative Damage and Neurodegenerative Disorders. The Neuroscientist, 8, 323-334. https://doi.org/10.1177/107385840200800408

[9] Rahman, I., Marwick, J. and Kirkham, P. (2004) Redox Modulation of Chromatin Remodeling: Impact on Histone Acetylation and Deacetylation, NF- $\kappa$ B and Pro-Inflammatory Gene Expression. Biochemical Pharmacology, 68, 1255-1267. https://doi.org/10.1016/j.bcp.2004.05.042

[10] Valko, M., Leibfritz, D., Moncol, J., Cronin, M.T., Mazur, M. and Telser, J. (2007) Free Radicals and Antioxidants in Normal Physiological Functions and Human Disease. The International Journal of Biochemistry and Cell Biology, 39, 44-84. https://doi.org/10.1016/j.biocel.2006.07.001

[11] Wira, C.R., Fahey, J.V., Sentman, C.L., Pioli, P.A. and Shen, L. (2005) Innate and Adaptive Immunity in Female Genital Tract: Cellular Responses and Interactions. Immunological Reviews, 206, 306-335. https://doi.org/10.1111/j.0105-2896.2005.00287.x

[12] Hanisch, U.K. (2002) Microglia as a Source and Target of Cytokines. Glia, 40, 140-155. https://doi.org/10.1002/glia.10161

[13] Gasque, P., Singhrao, S.K., Neal, J.W., Wang, P., Sayah, S., Fontaine, M. and Morgan, B.P. (1998) The Receptor for Complement Anaphylatoxin C3a Is Expressed by Myeloid Cells and Nonmyeloid Cells in Inflamed Human Central Nervous System: Analysis in Multiple Sclerosis and Bacterial Meningitis. The Journal of Immunolo$g y$, 160, 3543-3554.

[14] Nathan, C. (1992) Nitric Oxide as a Secretory Product of Mammalian Cells. The FASEB Journal, 6, 3051-3064. https://doi.org/10.1096/fasebj.6.12.1381691

[15] Dong, H., Zhang, X. and Qian, Y. (2014) Mast Cells and Neuroinflammation. Medical Science Monitor Basic Research, 20, 200-206. https://doi.org/10.12659/MSMBR.893093

[16] Mollace, V., Muscoli, C., Masini, E., Cuzzocrea, S. and Salvemini, D. (2005) Modulation of Prostaglandin Biosynthesis by Nitric Oxide and Nitric Oxide Donors. Pharmacological Reviews, 57, 217-252. https://doi.org/10.1124/pr.57.2.1

[17] Wu, J., Rutkowski, D.T., Dubois, M., Swathirajan, J., Saunders, T., Wang, J. and Kaufman, R.J. (2007) ATF6 $\alpha$ Optimizes Long-Term Endoplasmic Reticulum Function to Protect Cells from Chronic Stress. Developmental Cell, 13, 351-364. 
https://doi.org/10.1016/j.devcel.2007.07.005

[18] Almeida, J.R.G.D.S., Souza, G.R., Silva, J.C., Saraiva, S.R.G.D.L., Júnior, R.G.D.O., Quintans, J.D.S.S. and Junior, L.J.Q. (2013) Borneol, a Bicyclic Monoterpene Alcohol, Reduces Nociceptive Behavior and Inflammatory Response in Mice. The Scientific World Journal, 2013, Article ID: 808460.

[19] Netea, M.G., Kullberg, B.J. and Van Der Meer, J.W. (2000) Circulating Cytokines as Mediators of Fever. Clinical Infectious Diseases, 31, S178-S184. https://doi.org/10.1086/317513

[20] Edwards, S.W. (2005) Biochemistry and Physiology of the Neutrophil. Cambridge University Press, Cambridge.

[21] Valko, M., Rhodes, C., Moncol, J., Izakovic, M.M. and Mazur, M. (2006) Free Radicals, Metals and Antioxidants in Oxidative Stress-Induced Cancer. Chemico-Biological Interactions, 160, 1-40. https://doi.org/10.1016/j.cbi.2005.12.009

[22] Wojtaszek, P. (1997) Oxidative Burst: An Early Plant Response to Pathogen Infection. Biochemical Journal, 322, 681-692. https://doi.org/10.1042/bj3220681

[23] Badwey, J.A. and Karnovsky, M.L. (1980) Active Oxygen Species and the Functions of Phagocytic Leukocytes. Annual Review of Biochemistry, 49, 695-726. https://doi.org/10.1146/annurev.bi.49.070180.003403

[24] Babior, B.M. (2000) Phagocytes and Oxidative Stress. The American Journal of Medicine, 109, 33-44. https://doi.org/10.1016/S0002-9343(00)00481-2

[25] Heyneman, R.A. and Vercauteren, R.E. (1984) Activation of a NADPH Oxidase from Horse Polymorphonuclear Leukocytes in a Cell-Free System. Journal of Leukocyte Biology, 36, 751-759. https://doi.org/10.1002/jlb.36.6.751

[26] Dedon, P.C. and Tannenbaum, S.R. (2004) Reactive Nitrogen Species in the Chemical Biology of Inflammation. Archives of Biochemistry and Biophysics, 423, 12-22. https://doi.org/10.1016/j.abb.2003.12.017

[27] Schottenfeld, D. and Beebe-Dimmer, J. (2006) Chronic Inflammation: A Common and Important Factor in the Pathogenesis of Neoplasia. CA: A Cancer Journal for Clinicians, 56, 69-83. https://doi.org/10.3322/canjclin.56.2.69

[28] Roussos, A., Philippou, N. and Gourgoulianis, K.I. (2003) Helicobacter pylori Infection and Respiratory Diseases: A Review. World Journal of Gastroenterology, 9, 5-8. https://doi.org/10.3748/wjg.v9.i1.5

[29] Gencer, M., Ceylan, E., Zeyrek, F.Y. and Aksoy, N. (2007) Helicobacter pylori Seroprevalence in Patients with Chronic Obstructive Pulmonary Disease and Its Relation to Pulmonary Function Tests. Respiration, 74, 170-175. https://doi.org/10.1159/000090158

[30] Jaiswal, M., LaRusso, N.F. and Gores, G.J. (2001) Nitric Oxide in Gastrointestinal Epithelial Cell Carcinogenesis: Linking Inflammation to Oncogenesis. American Journal of Physiology_ Gastrointestinal and Liver Physiology, 281, G626-G634. https://doi.org/10.1152/ajpgi.2001.281.3.G626

[31] Kelly, R.A., Balligand, J.L. and Smith, T.W. (1996) Nitric Oxide and Cardiac Function. Circulation Research, 79, 363-380. https://doi.org/10.1161/01.RES.79.3.363

[32] Asano, K., Chee, C.B., Gaston, B., Lilly, C.M., Gerard, C., Drazen, J.M. and Stamler, J.S. (1994) Constitutive and Inducible Nitric Oxide Synthase Gene Expression, Regulation, and Activity in Human Lung Epithelial Cells. Proceedings of the National Academy of Sciences of the United States of America, 91, 10089-10093. https://doi.org/10.1073/pnas.91.21.10089

[33] Pannu, R. and Singh, I. (2006) Pharmacological Strategies for the Regulation of In- 
ducible Nitric Oxide Synthase: Neurodegenerative versus Neuroprotective Mechanisms. Neurochemistry International, 49, 170-182. https://doi.org/10.1016/j.neuint.2006.04.010

[34] Abu-Soud, H.M., Loftus, M. and Stuehr, D.J. (1995) Subunit Dissociation and Unfolding of Macrophage NO Synthase: Relationship between Enzyme Structure, Prosthetic Group Binding, and Catalytic Function. Biochemistry, 34, 11167-11175. https://doi.org/10.1021/bi00035a023

[35] Moncada, S. and Higgs, E.A. (1995) Molecular Mechanisms and Therapeutic Strategies Related to Nitric Oxide. The FASEB Journal, 9, 1319-1330. https://doi.org/10.1096/fasebj.9.13.7557022

[36] Venema, R.C., Sayegh, H.S., Kent, J.D. and Harrison, D.G. (1996) Identification, Characterization, and Comparison of the Calmodulin-Binding Domains of the Endothelial and Inducible Nitric Oxide Synthases. Journal of Biological Chemistry, 271, 6435-6440. https://doi.org/10.1074/jbc.271.11.6435

[37] Cai, S., Khoo, J., Mussa, S., Alp, N.J. and Channon, K.M. (2005) Endothelial Nitric Oxide Synthase Dysfunction in Diabetic Mice: Importance of Tetrahydrobiopterin in eNOS Dimerisation. Diabetologia, 48, 1933-1940. https://doi.org/10.1007/s00125-005-1857-5

[38] Medzhitov, R. (2001) Toll-Like Receptors and Innate Immunity. Nature Reviews Immunology, 1, 135. https://doi.org/10.1038/35100529

[39] Anderson, K.V. (2000) Toll Signaling Pathways in the Innate Immune Response. Current Opinion in Immunology, 12, 13-19. https://doi.org/10.1016/S0952-7915(99)00045-X

[40] Wendehenne, D., Pugin, A., Klessig, D.F. and Durner, J. (2001) Nitric Oxide: Comparative Synthesis and Signaling in Animal and Plant Cells. Trends in Plant Science, 6, 177-183. https://doi.org/10.1016/S1360-1385(01)01893-3

[41] Klessig, D.F., Durner, J., Noad, R., Navarre, D.A., Wendehenne, D., Kumar, D. and Trifa, Y. (2000) Nitric Oxide and Salicylic Acid Signaling in Plant Defense. Proceedings of the National Academy of Sciences of the United States of America, 97, 8849-8855. https://doi.org/10.1073/pnas.97.16.8849

[42] Garthwaite, J. and Boulton, C.L. (1995) Nitric Oxide Signaling in the Central Nervous System. Annual Review of Physiology, 57, 683-706. https://doi.org/10.1146/annurev.ph.57.030195.003343

[43] Dauphinee, S.M. and Karsan, A. (2006) Lipopolysaccharide Signaling in Endothelial Cells. Laboratory Investigation, 86, 9-22. https://doi.org/10.1038/labinvest.3700366

[44] Aktan, F. (2004) iNOS-Mediated Nitric Oxide Production and Its Regulation. Life Sciences, 75, 639-653. https://doi.org/10.1016/j.lfs.2003.10.042

[45] Schroder, K., Hertzog, P.J., Ravasi, T. and Hume, D.A. (2004) Interferon- $\gamma$. An Overview of Signals, Mechanisms and Functions. Journal of Leukocyte Biology, 75, 163-189. https://doi.org/10.1189/jlb.0603252

[46] Grossmann, M., Nakamura, Y., Grumont, R. and Gerondakis, S. (1999) New Insights into the Roles of ReL/NF- $\kappa$ B Transcription Factors in Immune Function, Hemopoiesis and Human Disease. The International Journal of Biochemistry and Cell Biology, 31, 1209-1219. https://doi.org/10.1016/S1357-2725(99)00068-0

[47] Taniguchi, T. and Takaoka, A. (2001) A Weak Signal for Strong Responses: Interferon-Alpha/Beta Revisited. Nature Reviews Molecular Cell Biology, 2, 378-386. https://doi.org/10.1038/35073080

[48] López-Franco, O., Suzuki, Y., Sanjuán, G., Blanco, J., Hernández-Vargas, P., Yo, Y. 
and Gómez-Guerrero, C. (2002) Nuclear Factor- $\kappa$ B Inhibitors as Potential Novel Anti-Inflammatory Agents for the Treatment of Immune Glomerulonephritis. The American Journal of Pathology, 161, 1497-1505. https://doi.org/10.1016/S0002-9440(10)64425-2

[49] Qin, L., Liu, Y., Wang, T., Wei, S.J., Block, M.L., Wilson, B. and Hong, J.S. (2004) NADPH Oxidase Mediates Lipopolysaccharide-Induced Neurotoxicity and Proinflammatory Gene Expression in Activated Microglia. Journal of Biological Chemistry, 279, 1415-1421. https://doi.org/10.1074/jbc.M307657200

[50] Kar, S. and Kavdia, M. (2012) Impact of SOD on Endothelial Cell Free Radical Distribution during eNOS Uncoupling. The FASEB Journal, 26, 1098.

[51] Meissner, F., Seger, R.A., Moshous, D., Fischer, A., Reichenbach, J. and Zychlinsky, A. (2010) Inflammasome Activation in NADPH Oxidase Defective Mononuclear Phagocytes from Patients with Chronic Granulomatous Disease. Blood, 116, 1570-1573. https://doi.org/10.1182/blood-2010-01-264218

[52] Lambertucci, R.H., Hirabara, S.M., Silveira, L.D.R., Levada-Pires, A.C., Curi, R. and Pithon-Curi, T.C. (2008) Palmitate Increases Superoxide Production through Mitochondrial Electron Transport Chain and NADPH Oxidase Activity in Skeletal Muscle Cells. Journal of Cellular Physiology, 216, 796-804. https://doi.org/10.1002/jcp.21463

[53] Hamanaka, R.B. and Chandel, N.S. (2009) Mitochondrial Reactive Oxygen Species Regulate Hypoxic Signaling. Current Opinion in Cell Biology, 21, 894-899. https://doi.org/10.1016/j.ceb.2009.08.005

[54] Bokoch, G.M. and Diebold, B.A. (2002) Current Molecular Models for NADPH Oxidase Regulation by Rac GTPase. Blood, 100, 2692-2695.

https://doi.org/10.1182/blood-2002-04-1149

[55] Frey, R.S., Ushio-Fukai, M. and Malik, A.B. (2009) NADPH Oxidase-Dependent Signaling in Endothelial Cells: Role in Physiology and Pathophysiology. Antioxidants and Redox Signaling, 11, 791-810. https://doi.org/10.1089/ars.2008.2220

[56] Groemping, Y. and Rittinger, K. (2005) Activation and Assembly of the NADPH Oxidase: A Structural Perspective. Biochemical Journal, 386, 401-416. https://doi.org/10.1042/BJ20041835

[57] De Leo, F.R. and Quinn, M.T. (1996) Assembly of the Phagocyte NADPH Oxidase: Molecular Interaction of Oxidase Proteins. Journal of Leukocyte Biology, 60, 677-691. https://doi.org/10.1002/jlb.60.6.677

[58] Babior, B.M. (1999) NADPH Oxidase: An Update. Blood, 93, 1464-1476.

[59] Elbim, C. (2005) Phagocyte NADPH Oxidase: A Multicomponent Enzyme Essential for Host Defenses. Archivum Immunologiae et Therapiae Experimentalis, 53, 199-206.

[60] Franck, T., Kohnen, S., De la Rebière, G., Deby-Dupont, G., Deby, C., Niesten, A. and Serteyn, D. (2009) Activation of Equine Neutrophils by Phorbol Myristate Acetate or N-Formyl-Methionyl-Leucyl-Phenylalanine Induces a Different Response in Reactive Oxygen Species Production and Release of Active Myeloperoxidase. Veterinary Immunology and Immunopathology, 130, 243-250.

https://doi.org/10.1016/j.vetimm.2009.02.015

[61] Jones, G.E., Allen, W.E. and Ridley, A.J. (1998) The Rho GTPases in Macrophage Motility and Chemotaxis. Cell Adhesion and Communication, 6, 237-245. https://doi.org/10.3109/15419069809004479

[62] Hackam, D.J., Rotstein, O.D., Schreiber, A., Zhang, W.J. and Grinstein, S. (1997) 
Rho Is Required for the Initiation of Calcium Signaling and Phagocytosis by Fc $\gamma$ Receptors in Macrophages. Journal of Experimental Medicine, 186, 955-966. https://doi.org/10.1084/jem.186.6.955

[63] Bosch, E., Horwitz, J. and Bok, D. (1993) Phagocytosis of Outer Segments by Retinal Pigment Epithelium: Phagosome-Lysosome Interaction. Journal of Histochemistryand Cytochemistry, 41, 253-263. https://doi.org/10.1177/41.2.8419462

[64] Mercado, C. and Jaimes, E.A. (2007) Cigarette Smoking as a Risk Factor for Atherosclerosis and Renal Disease: Novel Pathogenic Insights. Current Hypertension Reports, 9, 66-72. https://doi.org/10.1007/s11906-007-0012-8

[65] McCormick, M.L., Gavrila, D. and Weintraub, N.L. (2007) Role of Oxidative Stress in the Pathogenesis of Abdominal Aortic Aneurysms. Arteriosclerosis, Thrombosis, and Vascular Biology, 27, 461-469. https://doi.org/10.1161/01.ATV.0000257552.94483.14

[66] Ignarro, L. (2005) No More Heart Disease: How Nitric Oxide Can Prevent-Even Reverse-Heart Disease and Strokes. St. Martin's Griffin, Macmillan.

[67] Wallace, J.L., Ignarro, L.J. and Fiorucci, S. (2002) Potential Cardioprotective Actions of No-Releasing Aspirin. Nature Reviews Drug Discovery, 1, 375-382. https://doi.org/10.1038/nrd794

[68] Chatterjee, A. and Catravas, J.D. (2008) Endothelial Nitric Oxide (NO) and Its Pathophysiologic Regulation. Vascular Pharmacology, 49, 134-140. https://doi.org/10.1016/j.vph.2008.06.008

[69] Ding, W., Hudson, L.G. and Liu, K.J. (2005) Inorganic Arsenic Compounds Cause Oxidative Damage to DNA and Protein by Inducing ROS and RNS Generation in Human Keratinocytes. Molecular and Cellular Biochemistry, 279, 105-112. https://doi.org/10.1007/s11010-005-8227-y

[70] Svobodova, A., Walterova, D. and Vostalova, J. (2006) Ultraviolet Light Induced Alteration to the Skin. Biomedical Papers-Palacky University in Olomouc, 150, 25-38. https://doi.org/10.5507/bp.2006.003

[71] Choudhari, S.K., Chaudhary, M., Gadbail, A.R., Sharma, A. and Tekade, S. (2014) Oxidative and Antioxidative Mechanisms in Oral Cancer and Precancer: A Review. Oral Oncology, 50, 10-18. https://doi.org/10.1016/j.oraloncology.2013.09.011

[72] Murakami, A. and Ohigashi, H. (2007) Targeting NOX, INOS and COX-2 in Inflammatory Cells: Chemoprevention Using Food Phytochemicals. International Journal of Cancer, 121, 2357-2363. https://doi.org/10.1002/ijc.23161

[73] Hall, D.T., Ma, J.F., Di Marco, S. and Gallouzi, I.E. (2011) Inducible Nitric Oxide Synthase (iNOS) in Muscle Wasting Syndrome, Sarcopenia, and Cachexia. Aging (Albany NY), 3, 702-715. https://doi.org/10.18632/aging.100358

[74] Murakami, A. (2009) Chemoprevention with Phytochemicals Targeting Inducible Nitric Oxide Synthase. In: Yoshikawa, T., Ed., Food Factors for Health Promotion, Vol. 61, Karger Publishers, Basel, Switzerland, 193-203. https://doi.org/10.1159/000212751

[75] Tak, P.P. and Firestein, G.S. (2001) NF- $\kappa$ B: A Key Role in Inflammatory Diseases. The Journal of Clinical Investigation, 107, 7-11. https://doi.org/10.1172/JCI11830

[76] Cave, A. (2009) Selective Targeting of NADPH Oxidase for Cardiovascular Protection. Current Opinion in Pharmacology, 9, 208-213. https://doi.org/10.1016/j.coph.2008.10.001

[77] Williams, H.C. and Griendling, K.K. (2007) NADPH Oxidase Inhibitors: New Antihypertensive Agents? Journal of Cardiovascular Pharmacology, 50, 9-16. 
https://doi.org/10.1097/FJC.0b013e318063e820

[78] Takeya, R., Ueno, N., Kami, K., Taura, M., Kohjima, M., Izaki, T., Nunoi, H. and Sumimoto, H. (2003) Novel Human Homologues of $\mathrm{p} 47^{\text {phox }}$ and $\mathrm{p} 67^{\text {phox }}$ Participate in Activation of Superoxide-Producing NADPH Oxidases. Journal of Biological Chemistry, 278, 25234-25246. https://doi.org/10.1074/jbc.M212856200

[79] Streeter, J., Thiel, W., Brieger, K. and Miller Jr, F.J. (2013) Opportunity Nox: The Future of NADPH Oxidases as Therapeutic Targets in Cardiovascular Disease. Cardiovascular Therapeutics, 31, 125-137. https://doi.org/10.1111/j.1755-5922.2011.00310.x

[80] Rainsford, K.D. (2007) Anti-Inflammatory Drugs in the 21st Century. In: Randall, E., Harris, R., et al., Eds., Inflammation in the Pathogenesis of Chronic Diseases, Springer, Dordrecht, 3-27. https://doi.org/10.1007/1-4020-5688-5_1

[81] Iwalewa, E.O., McGaw, L.J., Naidoo, V. and Eloff, J.N. (2007) Inflammation: The Foundation of Diseases and Disorders. A Review of Phytomedicines of South African Origin Used to Treat Pain and Inflammatory Conditions. African Journal of Biotechnology, 6, 2868-2885.

[82] Surveswaran, S., Cai, Y.Z., Corke, H. and Sun, M. (2007) Systematic Evaluation of Natural Phenolic Antioxidants from 133 Indian Medicinal Plants. Food Chemistry, 102, 938-953. https://doi.org/10.1016/j.foodchem.2006.06.033

[83] Shah, M.R., Arfan, M., Amin, H., Hussain, Z., Qadir, M.I., Choudhary, M.I. and Khan, I.U. (2012) Synthesis of New Bergenin Derivatives as Potent Inhibitors of Inflammatory Mediators NO and TNF- $\alpha$. Bioorganic and Medicinal Chemistry Letters, 22, 2744-2747. https://doi.org/10.1016/j.bmcl.2012.02.096

[84] Sutherland, L.R. and MacDonald, J.K. (2016) Oral 5-Aminosalicylic Acid for Maintenance of Remission in Ulcerative Colitis. Cochrane Database of Systematic Reviews, 9, Art. No. CD000544. https://doi.org/10.1002/14651858.CD000544.pub2

[85] Ristow, M. and Schmeisser, K. (2014) Mitohormesis: Promoting Health and Lifespan by Increased Levels of Reactive Oxygen Species (ROS). Dose-Response, 12, 288-341. https://doi.org/10.2203/dose-response.13-035.Ristow

[86] Balaban, R.S., Nemoto, S. and Finkel, T. (2005) Mitochondria, Oxidants, and Aging. Cell, 120, 483-495. https://doi.org/10.1016/j.cell.2005.02.001

[87] Alexeyev, M.F. (2009) Is There More to Aging than Mitochondrial DNA and Reactive Oxygen Species? The FEBS Journal, 276, 5768-5787. https://doi.org/10.1111/j.1742-4658.2009.07269.x

[88] Poljsak, B. (2011) Strategies for Reducing or Preventing the Generation of Oxidative Stress. Oxidative Medicine and Cellular Longevity, 2011, Article ID: 194586. https://doi.org/10.1155/2011/194586

[89] Bloom, B.S. (1988) Cost of Treating Arthritis and NSAID-Related Gastrointestinal Side-Effects. Alimentary Pharmacology and Therapeutics, 2, 131-139. https://doi.org/10.1111/j.1365-2036.1988.tb00772.x

[90] Hedner, T. and Everts, B. (1998) The Early Clinical History of Salicylates in Rheumatology and Pain. Clinical Rheumatology, 17, 17-25. https://doi.org/10.1007/BF01450953

[91] Laine, L., Bombardier, C., Hawkey, C.J., Davis, B., Shapiro, D., Brett, C. and Reicin, A. (2002) Stratifying the Risk of NSAID-Related Upper Gastrointestinal Clinical Events: Results of a Double-Blind Outcomes Study in Patients with Rheumatoid Arthritis. Gastroenterology, 123, 1006-1012. https://doi.org/10.1053/gast.2002.36013 


\section{List of Abbreviations}

AA: Arachidonic Acid

AP-1: Activating Protein-1

CGD: Chronic Granulomatous Disease

DAG: Diacylglycerol

DPI: Diphenyl iodonium

ER: Endoplasmic Reticulum

FAD: Flavin adenine dinucleotide

FBS: Fetal Bovine Serum

FMLP: Formylated peptides

GAP: GTPase activating protein

GNEF: Guanine Nucleotide Exchange Factor

GPCR: Gq-coupled receptors

IBD: Irritable bowel syndrome

IFNR1: Interferon Receptor-1

IFN- $\gamma$ : Interferon- $\gamma$

IKK: Inhibitor of $\kappa B$ Kinase

IL- $1 \beta$ : Interleukin- $1 \beta$

iNOS: inducible nitric oxide synthase

IP3: Inositol Trisphosphate

IRAK: Interleukin-1 Receptor-Associated Kinase

IRF1: Interferon Response Factor-1

JAK: Janus Kinase family

LBP: LPS-Binding Protein

LPS: Lipopolysaccharide

MPO: Myeloperoxidase

MyD88: Myeloid Differentiation Primary Response Gene88

NADPH: Nicotinamide adenine dinucleotide

NDKB: Nucleoside Diphosphate Kinase B

NF- $\kappa B$ : Nuclear Factor-Kb

nNOS: Neuronal nitric oxide synthase

NOS-2: Nitric Oxide Synthase

Nox: NADPH oxidase

NSAIDs: Non steroidalantiinflammatory drugs

$\mathrm{O}^{2-}$ : Superoxide

ONOO: Peroxy nitrite

Phox: Phagocytic oxidase

PIP2: Phosphatidylinositol Bisphosphate

PKC: Protein kinase $\mathrm{C}$

PLC $\beta$ : phospholipase $\mathrm{C} \beta$

RhoGDI: Rho GDP dissociation inhibitor

ROS: Reactive oxygen species

SOD: Superoxide Dismutase 
STAT: Signal Transducers and Activators of Transcription

TAB1: TAK1-Binding Protein-1

TLR: Toll like receptor

TNF- $\alpha$ : Tumor Necrosis Factor- $\alpha$

TRAF6: TNF Receptor-Associated Factor-6 